\title{
ANFIS Based Parameter Estimating of a Two- Phase Interleaved Dual Cascaded DC-DC Boost Converter for Fuel Cell Supplied Electric Vehicles
}

\author{
Selami Balci, Ahmet Kayabasi and Berat Yildiz
}

\begin{abstract}
Fuel cells (FCs), one of the renewable energy sources, have started to be preferred as a power source in electric vehicles in recent years and research studies are continuing on designs in this direction. Although their efficiency is low $<50 \%$, they produce Direct Current (DC) electrical energy by electrochemical conversion without requiring battery systems, which can be used in electric vehicle drive systems. There are zero-emission effects such as water and temperature rise with waste and environmental aspects. One of the major disadvantages is the DC voltage amplitude they produce is inversely proportional to the temperature increase. In this context, parameter estimation is required to adapt the fluctuating FC voltage to a certain value adaptively with the DC-DC boost converter circuit. In this study, parametric simulation studies were carried out with Ansys-Electronics 2019-R3 software to determine the DC voltage level of a certain number of series and parallel connected FC cells depending on different temperature values. Duty ratio values of two-phase interleaved dual cascaded DC-DC boost converter circuit for desired output voltage were determined by using Adaptive Nero-Fuzzy Inference System (ANFIS) modeling of 1300 data determined by simulation studies. Thus, the output voltage of the converter is adaptively fixed at a certain value.
\end{abstract}

Index Terms- ANFIS, Electric Vehicle, Fuel Cell, Interleaved Cascaded Boost Converter.

SELAMI BALCI, is with Department of Electrical-Electonics Engineering of Karamanoglu Mehmetbey University, Karaman, Turkey, (e-mail: sbalci@kmu.edu.tr).

(iD https://orcid.org/0000-0002-3922-4824

AHMET KAYABASI, is with Department of Electrical-Electonics Engineering of Karamanoglu Mehmetbey University, Karaman, Turkey, (email: ahmetkayabasi@kmu.edu.tr).

iD https://orcid.org/0000-0002-9756-8756

BERAT YILDIZ, is with Department of Electrical-Electonics Engineering of Karamanoglu Mehmetbey University, Karaman, Turkey, (e-mail: beratyildiz@kmu.edu.tr).

iD https://orcid.org/0000-0002-5675-6750

Manuscript received June 30, 2021; accepted October 18, 2021. DOI: $\underline{10.17694 / \text { bajece. } 940791}$

\section{INTRODUCTION}

$\mathrm{F}$ UEL CELLS (FCs) are electrochemical structures that use a chemical reaction like a battery in the production of DC electrical energy. Besides, they do not run out of energy as long as their fuel is supplied and there are no recharging requirements, such as batteries. FC systems use hydrogen gas and oxygen as input, and as output, DC electricity generates energy, and as waste to the environment, it produces only water and heat [1-2]. In recent years, researches and studies have been accelerated to make renewable energy sources widespread for zero-emissions with global warming effects. Also, renewable energy sources such as FCs are recommended to reduce fossil fuel consumption, especially in electric vehicles with the increasing use of green energy sources to prevent the lack of reserves of renewable fossil fuels and the possibility of depletion in the coming years and their negative effects on the environment [3]. Rapid developments in power electronics and fuel cell technology have led to significant improvements in fuel cell electric vehicles [4]. FCs are electrochemical devices that convert the chemical energy of hydrogen fuel into DC electrical energy and can meet the energy requirements of electric vehicles without encountering any charging problems. The most preferred FC in an application is polymer electrolyte membrane FC (PEMFC) with a more compact structure and low-temperature values. A single cell in an FC module of this type typically has a voltage of $0.6 \mathrm{~V}$. Therefore, in FC sources, modules are formed by serial/parallel connection of more than one cell and thus the desired DC voltage amplitude can be obtained [5-6].

The electrical systems of FC-sourced electric vehicles with batteries are often faced with the need to increase the low input voltage $(30-60 \mathrm{~V})$ to a higher voltage value $(360 \mathrm{~V})$ to provide the DC bus voltage for the inverter [7]. You also need $400 \mathrm{~V}$ to interface to the mains [8-9]. Therefore, an additional dc-dc boost converter circuit is required to compensate for FC voltage fluctuations [10]. Furthermore, the life of the fuel cell is influenced by the ripple amplitude in the input current of the power electronics converter circuit. Therefore, dc-dc converters for fuel cell applications require low input current fluctuations and multi-phase interleaved boost converter circuits are recommended [11]. 
Interleaved converter circuits are controlled by switching signals shifted by $360 / \mathrm{n}$ depending on the equal switching frequency and the number of phases $\mathrm{n}$ of the power switch for each phase. In the conventional DC-DC converter circuit, there may be difficulties when switching at very high frequencies for very large powers (tens of $\mathrm{kW}$ ). In Interleaved converters, depending on the number of phases, each power switch is driven at lower frequency values and the ripple frequency of converter output voltage is multiplied and the high-frequency effect is obtained. Thus, the parallel connection of conventional converter circuits provides equal power-sharing for the phases and low-reliability electromagnetic interference (EMI) provides high reliability and high efficiency in power electronics applications [12]. It is also preferred that the designed DC-DC converters are more compact for use in a limited volume, such as an electric vehicle. In this context, when the inductors are designed to be coupled in interleaved converter circuits, more compact designs can be obtained and the ripple amplitude of the converter output voltage can be adjusted by the magnetic coupling effect [13-15].

The major disadvantage of the fuel cells is the low levels of efficiency and the release of heat during operation and consequently the increase in temperature and the decrease in the DC voltage level. On account of this, the design of the DC-DC power converter circuit used in the outputs of FC sources is very important and adaptive changes in voltage level need to be compensated. Therefore, in terms of both the use of the voltage generated from FCs within the electric vehicle and its adaptation to the grid, power electronics circuit designs are important and the control circuit of this system is controlled separately for each block of power conversion (Figure 1).

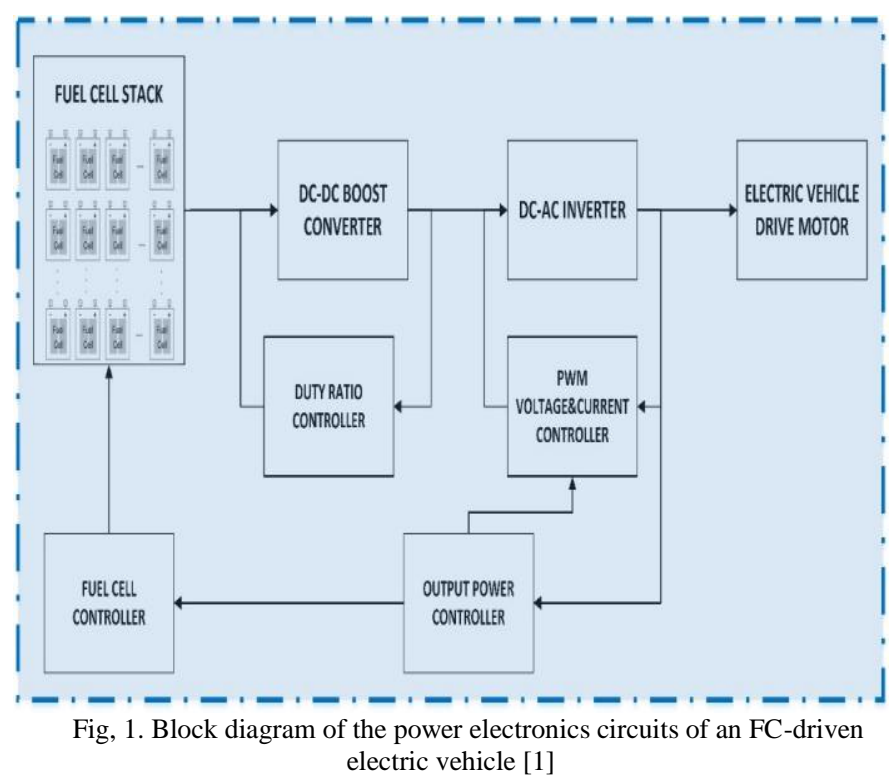

The use of ANFIS for parameter estimation in the design of power electronic circuits is very useful for predicting the performance of complex systems and offers a very low error rate modeling. In this context, a PEMFC system with a rated power of $5 \mathrm{~kW}$ was modeled with an extremely high accuracy performance with ANFIS. The experimental number was obtained by using 7 input / 2 output parameters as soon as possible. Thus, by taking data from PEMFC, an ANFIS training set is created to manage this system and can be trained to predict system behavior without requiring any equation [15]. ANFIS, one of the popular methods for modeling nonlinear complex system behavior, is frequently preferred in many engineering applications such as control systems of power electronic circuits, pattern recognition and image processing in information systems. In the modeling with neural network structures in the ANFIS structure, the behavior of input and output parameters must be introduced to the network to be trained using an algorithm. In this modeling, multi-layer networks are blocks that can bring a parameter that can be measured by experimental or simulation studies to the desired degree of accuracy [15]. For fuel cell-based power electronics applications, a basic and lifelike fuel cell must be modeled. Furthermore, ANFIS may be used to estimate the relationship between voltage and temperature to determine the nonlinear behavior of the fuel cell module due to temperature rise [16]. Traditionally, performance optimization is performed offline because it requires a lot of time and high computing capabilities. To activate online parameter updating and simplify the management process, [17] proposes a new and specific technique using Artificial Neural Network (ANN). For the training and testing of ANN, parameter estimates of the fuel cell are made by using the data obtained from simulation studies [18].

In this study, temperature-dependent changes in DC output voltage obtained by connecting a certain number of seriesparallel models were modeled by using Ansys-Electronics 2019-R3 software with parametric simulation [19] in the range of $30-50{ }^{\circ}$ C. To keep the output voltage constant at the desired level, the output voltage level estimation according to the input variables such as the number of cells connected in series and parallel and the temperature was tested with ANFIS and a certain number of data were received from the 1300 data obtained and trained in the ANFIS network for verification. Thus, it is recommended to make parameter estimation with ANFIS to use the electrical energy obtained from FCs effectively and to make an adaptive voltage controller in the two-phase IDCB converter circuit. The most important contribution of this study to the previous literature is an adaptive controlled two-phase dual boost converter circuit for duty control in DC voltage value fluctuations provided from fuel cells used in electric vehicle power systems. Thus, it is shown that all parameters can be monitored with parametric simulation supported artificial intelligence techniques before the prototype power electronics are installed.

\section{PARAmetric Simulation StUdies}

In parametric simulation studies, three different input parameters were determined in the interface of the FC cells connected in series or parallel to each other to determine the 
performance of FC sources under more realistic conditions. Thus, different voltage data produced by FC cells were obtained by parametric simulation studies depending on the number of connected cells in parallel or series and the temperature values of the system (Figure 2 and Figure 3).

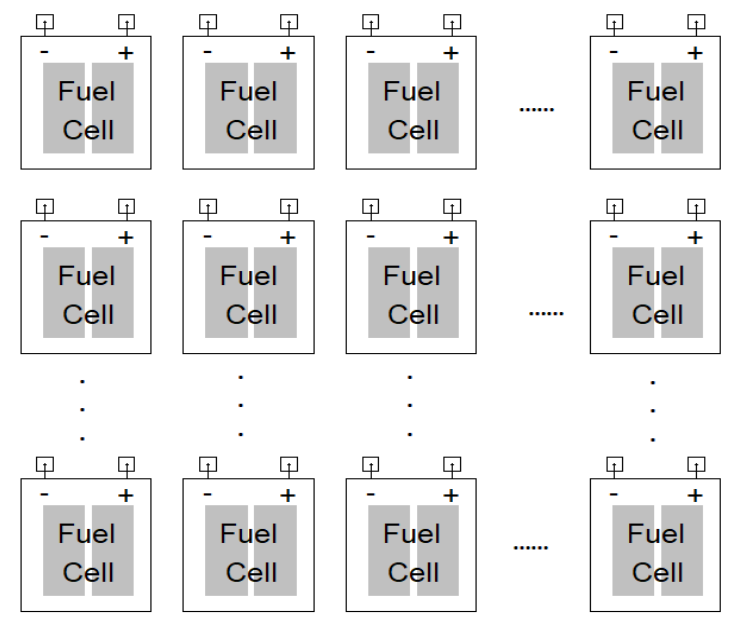

Fig. 2. Serial-parallel connected FCs [19].

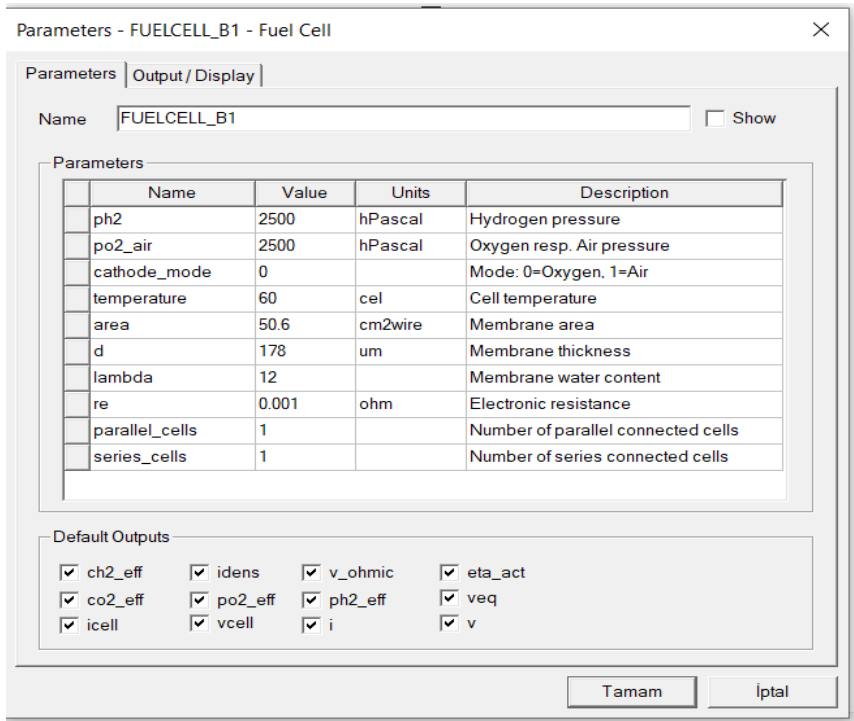

Fig. 3. Serial-parallel connected FCs and parametric data [19].

In Table 1, cell temperature (Tc), the number of seriesconnected cells (Ns) and the number of parallel-connected cells (Np) were used as input variables for parametric simulation of FC sources. ANFIS test and training data were obtained by operating for specific value ranges.

The IDCB converter circuit has been chosen as a two-phase interleaved structure in order to provide the DC bus voltage $(400 \mathrm{~V})$ required by the inverter in electric vehicle applications. The switching frequency value is determined as $20 \mathrm{kHz}$ for each phase with 180 degree phase difference and its effect on the output voltage is determined as $40 \mathrm{kHz}$. In this context, the values of the passive circuit elements have been established in the simulation circuit in such a way that the output voltage ripple value under constant load does not exceed $10 \%$ according to the $20 \mathrm{kHz}$ switching frequency value. One of the most popular high-gain DC-DC power converter circuits without using a transformer is the two-phase interleaved dual cascaded boost converter circuit. In the circuit given in Figure 8, there are four power switches operating with the same duty ratio (D) as the switching frequency (fs). Thus, the values of inductors L1(L3) and L2(L4) can be determined separately for the continuous conduction mode as given in Equations 1 and 2 [14].

TABLE I. THE PARAMETRIC SIMULATIONS' TECHNICAL

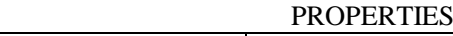

\begin{tabular}{|c|c|c|}
\hline Parameters & Value & Step Interval \\
\hline $\mathrm{Tc}$ & $30-50{ }^{\circ} \mathrm{C}$ & $1{ }^{\circ} \mathrm{C}$ \\
\hline $\mathrm{Np}$ & $1-10$ & constant \\
\hline $\mathrm{Ns}$ & $1-10$ & constant \\
\hline FC sourcevoltage & $30-48 \mathrm{~V}$ & $1 \mathrm{~V}$ \\
\hline $\mathrm{D}$ & $0.1-0.7$ & 0.05 \\
\hline$f \mathrm{~s}$ & $20 \mathrm{kHz}$ & constant \\
\hline L1-L3 & $100 \mu \mathrm{H}$ & constant \\
\hline L2-L4 & $250 \mu \mathrm{H}$ & constant \\
\hline C1-C2 & $100 \mu \mathrm{F}$ & constant \\
\hline RL & $25 \Omega$ & constant \\
\hline
\end{tabular}

$L_{1}=\frac{V_{i n}}{2 \cdot f_{s} \cdot I_{o}} D(1-D)^{2}$

$$
L_{2}=\frac{V_{i n}}{2 \cdot f_{s} \cdot I_{o}} D
$$

In addition, the capacitor selection, which can keep the ripple value of the output voltage given by Equation 3 at a certain level [18], is also determined depending on the switching frequency $(\mathrm{fs}=1 / \mathrm{T})$ and switching duty ratio and is given in Table 1.

$\Delta v_{o}=\frac{1}{C} \frac{I_{o} D}{f_{s}}$

\section{RESULTS AND DISCUSSION}

ANFIS is a system in which artificial neural networks of artificial intelligence methods and fuzzy logic are applied together as an inference system derived from mathematical expressions. This system is an artificial intelligence method with the ability to perform learning and parallel computing with artificial neural networks and inferential with fuzzy logic [20]. Only fuzzy logic does not have a learning function against external interferences that adversely affect the design of environmental control systems and is vulnerable to distortions. Therefore, expert opinion is always needed in the determination of system parameters. Therefore, artificial intelligence techniques such as ANN can be used against high mathematical problems arising from expert opinion in control systems involving complex relationships. In this study, the ANFIS structure, which proposes to solve the mathematical 
complexity that occurs in the determination of FL parameters, with ANN was used. ANFIS can assign all the rules that can be created according to the system designed for the problem to be solved, and it can also allow the relevant rules to be appointed by the experts. Therefore, the problem that is tried to be solved without expert opinions in the artificial neural networks, together with the inclusion of the fuzzy logic inference system, allows the experts to benefit from their opinions. This makes it possible to achieve better results.

In this study, parametric simulation studies were carried out with Ansys-Electronics 2019-R3 software to determine the DC voltage level of a certain number of series and parallel connected FC cells depending on different temperature values. After the simulation, a dataset of 1300 data was created, consisting of the number of parallel-connected cells (Np), the number of series-connected cells (Ns) and temperature that affect the electrical energy obtained from FC. The duty ratio values for the desired output voltage of the two-phase interleaved dual cascaded DC-DC boost converter circuit were determined by training the data set with the Adaptive NeroFuzzy Inference System (ANFIS) model. In this way, the optimum values of the parameters to be used in adaptive voltage control design are tried to be determined. The flow diagram of ANFIS system modeling is given in Figure 4.

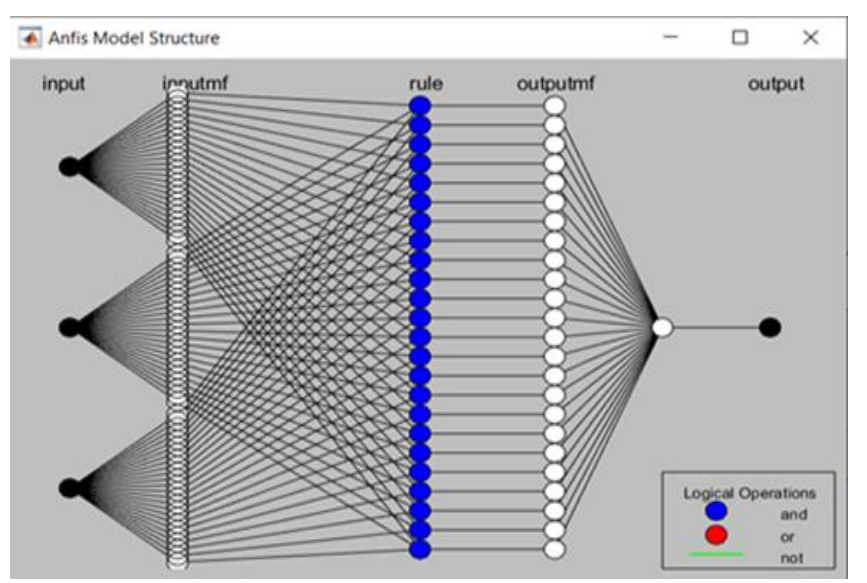

Fig. 4. The flow diagram of ANFIS system modeling

Adaptive networks consist of nodes and directional links that connect these nodes. The learning function in the modeled network structures is realized by updating the node parameters and reducing the estimated error between input and output to a minimum [21]. In the ANFIS network structure, the functions of the nodes in the same layer are equal. The output of the nodes in the Fuzzification layer is obtained as a result of membership functions applied to the values in the input layer. These outputs have membership ratings and are forwarded as input to the rule layer. In this network model, the Gaussian activation membership function is used to separate input values into fuzzy sets [22]. The nodes in the Rule layer contain rules created by Sugeno's fuzzy logic inference system. These rules can be defined in the form of a simple logical proposition, as in conventional logic. Here, the conjunction 'and/or' is used, which connects the value (proposition) in two different sets. These conjunctions actually define the relationship between these two fuzzy sets. In this way, we create the rules that will be kept in the knowledge base of the fuzzy system with the definitions we have made before. Each node output in Rule layer refers to the triggering level of a created rule. Nodes in the rule layer form the input value of the Normalization layer. Normalized rule layer outputs are called normalized triggering levels. The result values assigned to the weight value of a rule given in each node in the de-fuzzification layer are calculated. The parameters in this layer are called the result parameters. In the last layer, there is a summation layer consisting of only one node [23]. The actual value of the ANFIS system is obtained by summing the output value of each node in the defuzzification layer. The performance of the ANFIS model is a function of the error between the output produced by the actual system, which corresponds to a particular input signal, and the output produced by the model against the same input. The most common measure used in evaluating model performance is the root mean square error between the actual system output and the network prediction output. The data set contains 1300 data for each input parameter. The training error graph obtained as a result of the training of this data set in ANFIS is as in Figure 5.
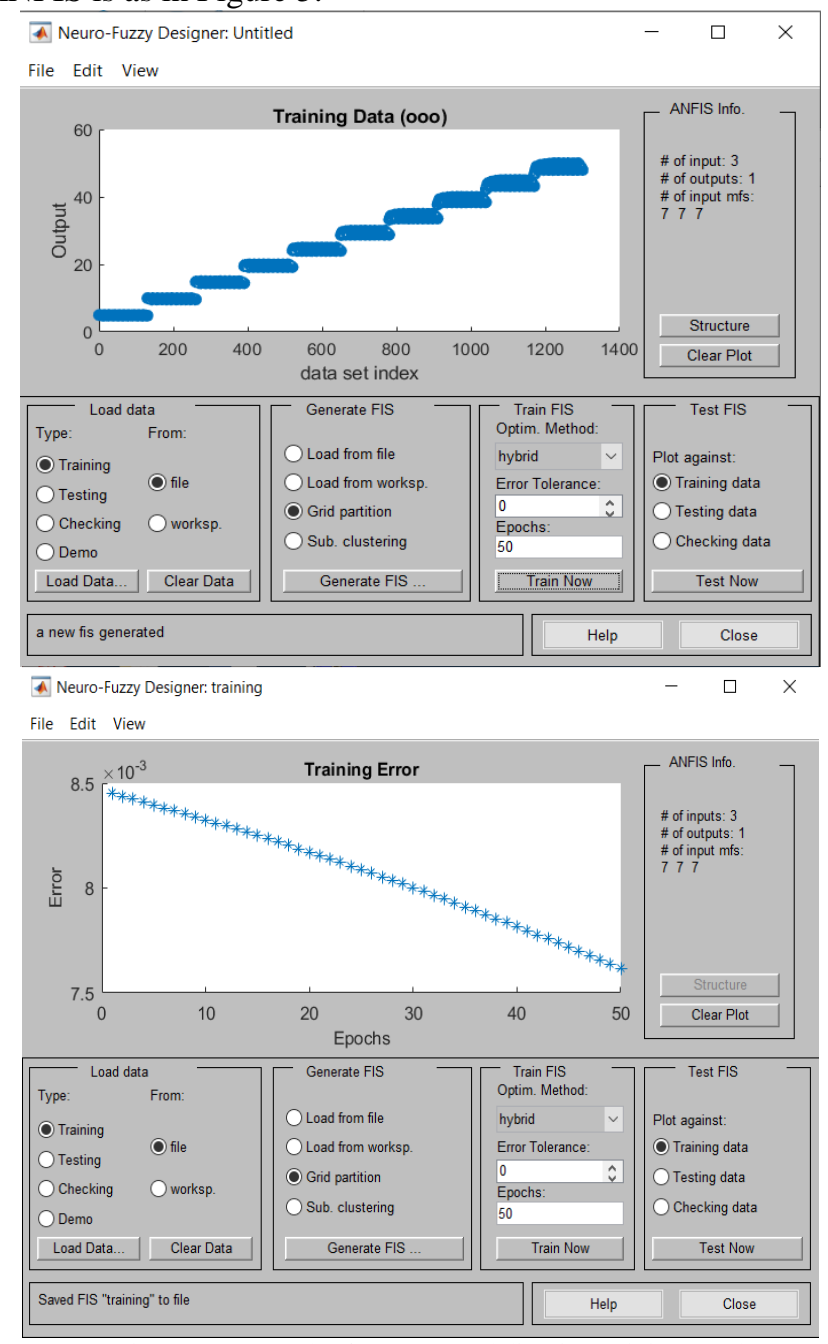

Fig. 5. Error graph of ANFIS modeling in Training result 
As can be seen from the graphs and results, the probability of the estimation of the voltage value in the result of the 3 parameters trained in 50 epochs using Sub-clustering is less than $1 \%$. Besides, the figure below shows the number of parameters generated during training (Figure 6).

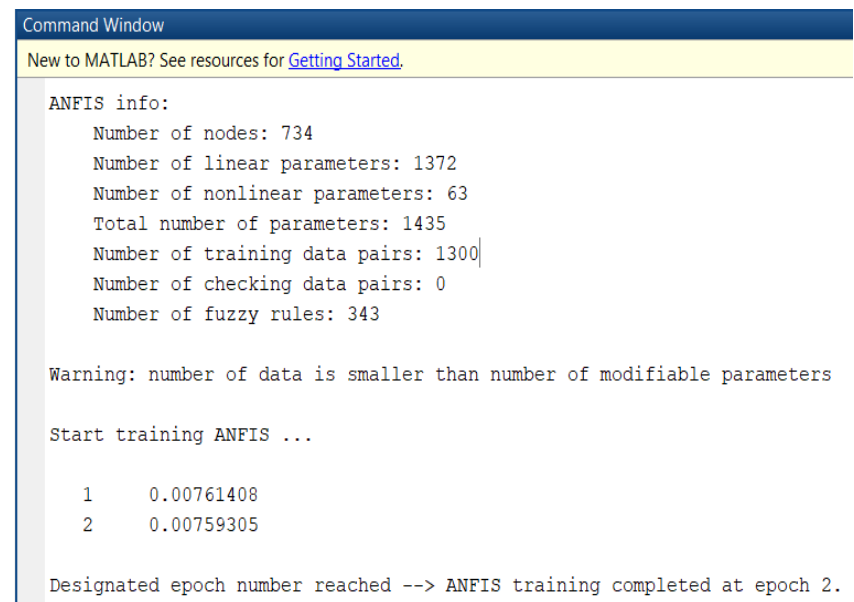

Fig. 6. Number of parameters generated during training at ANFIS

According to the 25 Fuzzy rules function according to the input parameters found in the data set, the estimation of the voltage value is given in Figure 7.

In the rule-based example, when the number of parallel cells (input 1) is approximately 7 , the number of serial cells (input 2) is 7, and the temperature is 50 degrees, the generated voltage value is about $34.2 \mathrm{~V}$. When this value is compared with the value in our data set, the voltage value obtained in the data set in the same parameters is $33.9 \mathrm{~V}$. Therefore, the ANFIS model, which will be used to estimate the optimum voltage value, gives quite reliable results. In addition, 30 randomly selected data from the simulation data that were not trained before were tested with ANFIS and the test results are presented in the table. Therefore, the ANFIS model, which will be used to estimate the optimum voltage value, gives quite reliable results with a $0.001 \%$ RMSE.

Parametric simulation studies for the duty controller against voltage drops in the input voltage of the power electronics circuit have been carried out with the proposed IDCB circuit [24] in Figure 8. The circuit used in the simulation was run with values given in Table 1 which the FC source output voltage $30-48 \mathrm{~V}$, duty ratio value in the range 0.1-0.7 and switching frequency $20 \mathrm{kHz}$. Thus, the parametric 3D voltage graph shown in Figure 9 is obtained.

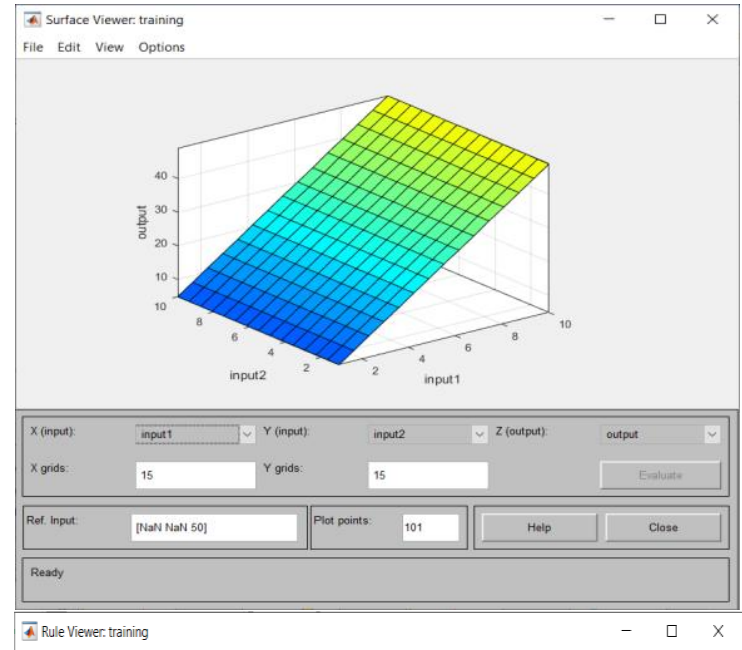

File Edit Wew Options

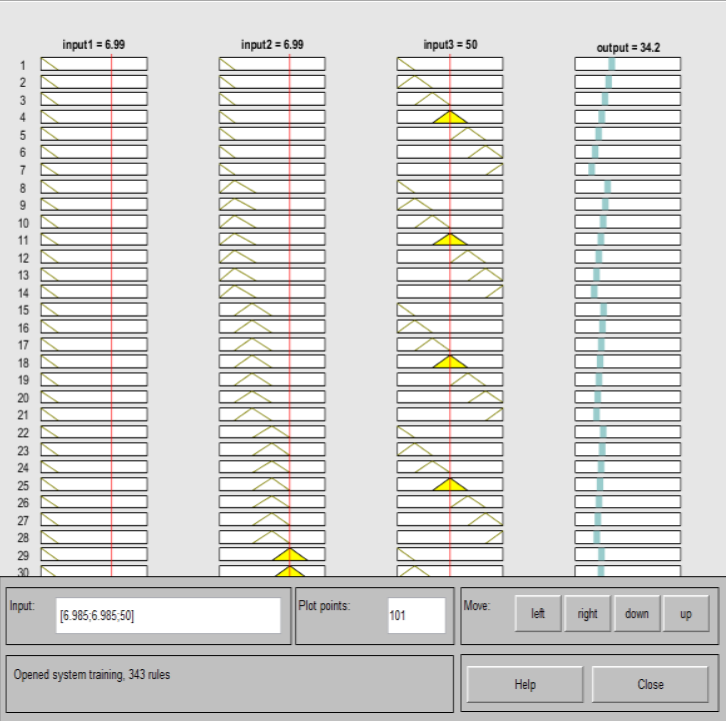

Fig. 7. Testing for the ANFIS Model

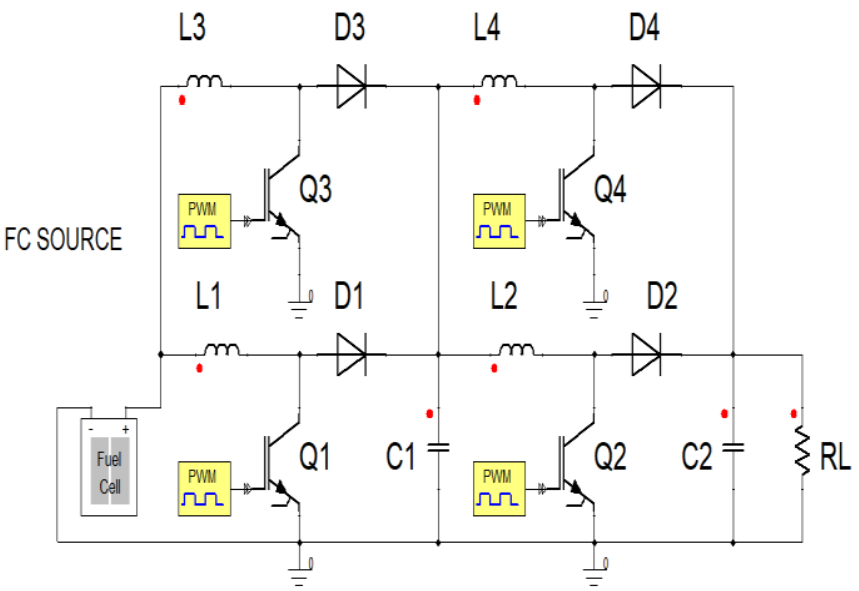

Fig. 8. The parametric simulation circuits for two-phase IDCB converter circuit 
TABLE II. COMPARISON OF SIMULATION DATASET WITH ANFIS PREDICTION VALUES

\begin{tabular}{|c|c|c|c|c|c|}
\hline No\# & Np & Ns & Tc & $\begin{array}{c}\text { FC sourcevoltage } \\
\text { (dataset) }\end{array}$ & $\begin{array}{c}\text { FC sourcevoltage } \\
\text { (ANFIS) }\end{array}$ \\
\hline 1 & 7 & 6 & 55 & 32.49814 & 32.5541 \\
\hline 2 & 1 & 4 & 55 & 4.642613 & 4.6485 \\
\hline 3 & 9 & 5 & 70 & 41.3422 & 41.342 \\
\hline 4 & 10 & 4 & 30 & 47.20361 & 47.2528 \\
\hline 5 & 7 & 8 & 60 & 32.38582 & 32.3622 \\
\hline 6 & 8 & 6 & 50 & 37.26743 & 37.2492 \\
\hline 7 & 8 & 4 & 80 & 36.47222 & 36.4855 \\
\hline 8 & 7 & 6 & 25 & 33.14966 & 33.1453 \\
\hline 9 & 2 & 8 & 20 & 9.501816 & 9.5043 \\
\hline 10 & 1 & 4 & 30 & 4.720431 & 4.714 \\
\hline 11 & 3 & 8 & 45 & 14.02237 & 14.0064 \\
\hline 12 & 1 & 5 & 55 & 4.642614 & 4.6335 \\
\hline 13 & 1 & 10 & 55 & 4.642616 & 4.6205 \\
\hline 14 & 9 & 2 & 45 & 42.06614 & 42.0356 \\
\hline 15 & 7 & 9 & 60 & 32.38583 & 32.3546 \\
\hline 16 & 4 & 2 & 35 & 18.82013 & 18.8854 \\
\hline 17 & 10 & 4 & 65 & 46.10197 & 46.0955 \\
\hline 18 & 1 & 4 & 45 & 4.674127 & 4.6807 \\
\hline 19 & 5 & 4 & 30 & 23.602 & 23.6647 \\
\hline 20 & 4 & 8 & 55 & 18.57043 & 18.544 \\
\hline 21 & 8 & 6 & 35 & 37.64042 & 37.5558 \\
\hline 22 & 8 & 9 & 25 & 37.8854 & 37.9125 \\
\hline 23 & 2 & 9 & 40 & 9.379324 & 9.3807 \\
\hline 24 & 5 & 9 & 20 & 23.75449 & 23.7434 \\
\hline 25 & 5 & 4 & 60 & 23.13268 & 23.1355 \\
\hline 26 & 7 & 10 & 45 & 32.71881 & 32.7265 \\
\hline 27 & 8 & 4 & 70 & 36.74859 & 36.7652 \\
\hline 28 & 3 & 7 & 80 & 13.67717 & 13.6874 \\
\hline 29 & 7 & 7 & 40 & 32.82748 & 32.8323 \\
\hline 30 & 7 & 4 & 75 & 32.03585 & 32.053 \\
\hline \multicolumn{5}{|c|}{ Root Mean Square Error (RMS) \% } & 0.001 \\
\hline
\end{tabular}

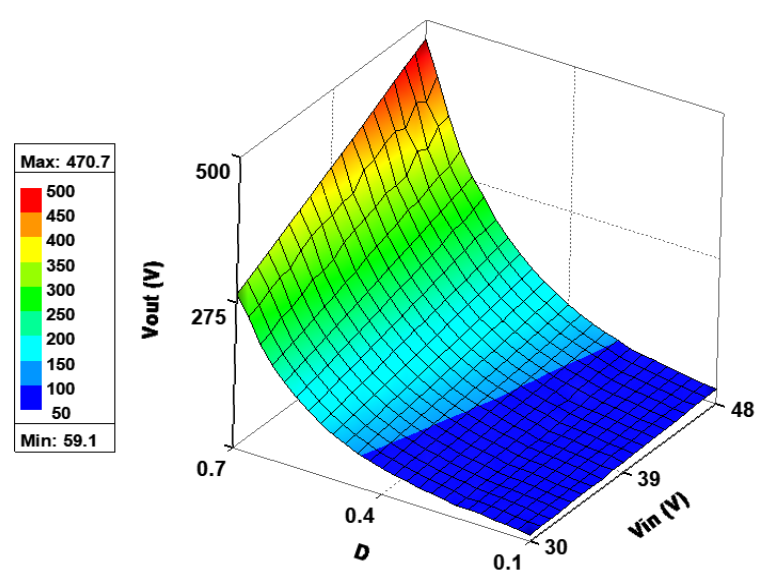

Fig. 9. The parametric 3D voltage graph

For the proposed duty ratio controller, a two-phase IDCB circuit was simulated based on the data obtained to test the performance of FC based system. According to the graph shown in Figure 10, the initial duty ratio is 0.58 , the converter input voltage is $48 \mathrm{~V}$ and $\mathrm{FC}$ cell temperature is $40^{\circ} \mathrm{C}$, while the output DC bus voltage is $400 \mathrm{~V}$. When the temperature is $60{ }^{\circ} \mathrm{C}$ at $40 \mathrm{~ms}$, the converter input voltage decreases from 48 $\mathrm{V}$ to $39 \mathrm{~V}$ and the converter output voltage decreases to approximately $325 \mathrm{~V}$. To compensate for this situation, the duty controller has increased the key duty ratio from 0.58 to
0.64 so that the DC bus voltage is restored to $400 \mathrm{~V}$ for $10 \mathrm{~ms}$. Thus, when the voltage fluctuation in FC sources changes depending on the temperature, the DC bus voltage at the converter output can be kept constant at $400 \mathrm{~V}$ with a duty controller.

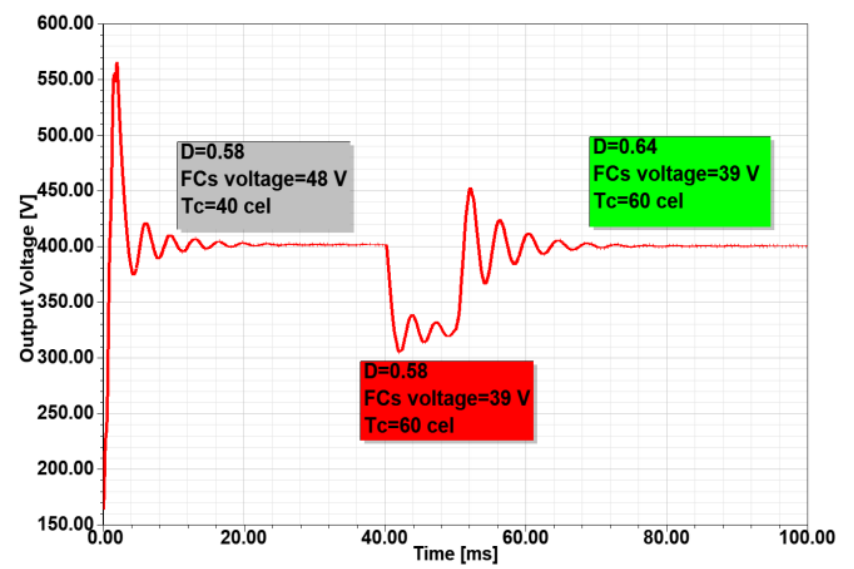

Fig. 10. The output voltage waveform of IDCB circuit with duty controller

Parametric analysis graph showing the transient analysis of output voltage with different variations based on parametric simulation studies is given in Figure 11.

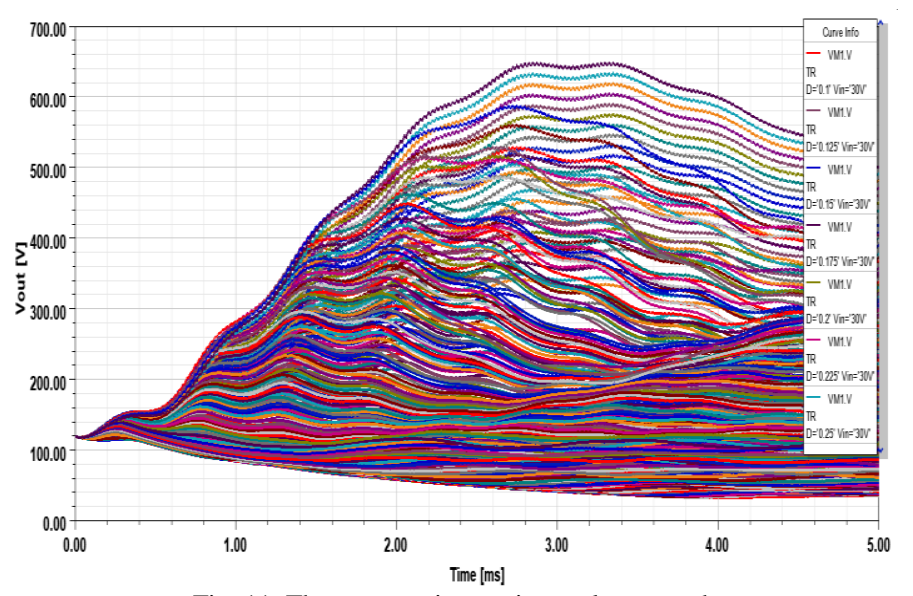

Fig. 11. The parametric transient voltage graph

\section{CONCLUSION}

The output voltage value of the FCs which IDCB converter input voltage are reduced by the cell temperature rise, and the parameter estimation of FCs is the most important issue to stable for the output voltage fluctuations of the converter. In this paper, the adaptive duty controller is designed to convert DC electrical energy obtained from FC sources to the stable voltage level with the interleaved boost converter circuit, and a two-phase IDCB converter is proposed for the FC sourced electric vehicles. To keep the output voltage constant at the desired level, the output voltage level estimation according to the input variables such as the number of cells connected in series and parallel and the temperature was tested with ANFIS and a certain number of data were received from the 1300 data obtained and trained in the ANFIS network for verification with parametric simulation in the range of $30-50{ }^{\circ} \mathrm{C}$. Thus, the 
DC bus voltage can be kept constant at $400 \mathrm{~V}$ with an adaptive duty controller for any voltage value of the FC in the 30-48 V range. Also, a two-phase converter with current sharing for 20 $\mathrm{kHz}$ switching frequency is $40 \mathrm{kHz}$ output voltage ripple effect has been achieved with IDCB converter circuit. Finally, the most important study to be done in the future is to experimentally construct this power electronics circuit and test the ability of the proposed control technique.

\section{REFERENCES}

[1] W. Choi, PN. Enjeti, JW. Howze. "Development of an equivalent circuit model of a fuel cell to evaluate the effects of inverter ripple current." Nineteenth Annual IEEE Applied Power Electronics Conference and Exposition, 2004, pp. 355-361.

[2] JW. Jung, A. Keyhani. "Control of a fuel cell-based Z-source converter." IEEE Transactions on Energy Conversion, vol. 22. 2, 2007, pp. 467-476.

[3] Z. Zhang, et al., "A review and design of power electronics converters for fuel cell hybrid system applications." Energy Procedi, vol. 20, 2012, pp. 301-310.

[4] HJ. Chiu, LW. Lin. "A bidirectional DC-DC converter for fuel cell electric vehicle driving system." IEEE Transactions on Power Electronics, vol. 21. 4, 2006, pp. 950-958.

[5] A. Shahin, M. Hinaje, J.P. Martin, S. Pierfederici, S. Raël, B. Davat. "High Voltage Ratio DC-DC Converter for Fuel-Cell Applications." IEEE Transactions on Industrial Electronics, vol. 57. 12, 2010, pp. 39443955.

[6] M. Bahrami, J.P. Martin, G. Maranzana, S. Pierfederici, M. Weber, F. Meibody-Tabar, M. Zandi. "Design and modeling of an equalizer for fuel cell energy management systems." IEEE Transactions on Power Electronics. Doi:10.1109/TPEL.2019.2899150, 2019.

[7] C. Liu, A. Johnson, JS. Lai. "A novel three-phase high-power softswitched DC/DC converter for low-voltage fuel cell applications." IEEE Transactions on Industry Applications, vol. 41. 6, 2005, pp. 1691-1697.

[8] KC. Tseng, JT. Lin, CC. Huang. "High step-up converter with threewinding coupled inductor for fuel cell energy source applications." IEEE Transactions on Power Electronics, vol. 30. 2, 2004, pp. 574-581.

[9] M. Nymand, MA. Andersen. "High-efficiency isolated boost DC-DC converter for high-power low-voltage fuel-cell applications." IEEE Transactions on industrial electronics, vol. 57. 2, 2010, pp. 505-514.

[10] D. M. Bellur and M. K. Kazimierczuk, "DC-DC converters for electric vehicle applications." 2007 Electrical Insulation Conference and Electrical Manufacturing Expo, 2007, pp. 286-293, Doi:10.1109/EEIC.2007.4562633.

[11] CT. Pan, CM. Lai. "A high-efficiency high step-up converter with low switch voltage stress for fuel-cell system applications." IEEE Transactions on Industrial Electronics, vol. 57. 6, 2009, pp. 1998-2006.

[12] P. Thounthong, B. Davat. "Study of a multiphase interleaved step-up converter for fuel cell high power applications." Energy Conversion and Management, vol. 51. 4, 2010, pp. 826-832.

[13] T. Takiguchi, K. Furukawa, K. Matsumura and H. Koizumi. "Interleaved soft-switching multilevel boost converter with coupled inductor." IECON 2015 - 41st Annual Conference of the IEEE Industrial Electronics Society, 2015, pp. 649-654, Doi:10.1109/IECON.2015.7392173.

[14] S. Balci, N. Altin, H. Komurcugil, Sefa I, "Performance Analysis of Interleaved Quadratic Boost Converter with Coupled Inductor for Fuel Cell Applications." 42st Annual Conference of the IEEE Industrial Electronics Society, IECON, Italy, 2016, pp. 3541-3546.

[15] M. Amin, et al. "Analysis and design of a high efficiency bidirectional DC-DC converter for battery and ultracapacitor applications." Simulation Modelling Practice and Theory, vol. 19. 7, 2011, pp. 16511667.

[16] AU. Chávez-Ramírez AU et al., "High power fuel cell simulator based on artificial neural network." International Journal of Hydrogen Energy, vol. 35. 21, 2010, pp. 12125-12133.

[17] X. Kong, AM. Khambadkone. "Modeling of a PEM fuel-cell stack for dynamic and steady-state operation using ANN-based submodels." IEEE Transactions on Industrial Electronics, vol. 56. 12, 2009, pp. 4903-4914.

[18] S. Balci, A. Kayabasi, B. Yildiz. "Artificial Neural Network Based Estimation of the Output Ripple of the DC-DC Boost Battery Charger for EVs." 6th Eur. Conf. Ren. Energy Sys., 2018, Istanbul, Turkey.
[19] S. Balci, A. Kayabasi, B. Yildiz. "Estimation of Fuel Cell Parameters with ANFIS." 7th Eur. Conf. Ren. Energy Sys., 2019, Madrid, Spain.

[20] AM. Azmy, I. Erlich. "Online optimal management of PEM fuel cells using neural networks." IEEE Transactions on Power Delivery, vol. 20. 2, 2005, pp. 1051-1058.

[21] JS. Jang. "ANFIS: adaptive-network-based fuzzy inference system." IEEE Transactions on Systems, Man, and Cybernetics, vol. 23. 3, 1993, pp. 665-685.

[22] JSR. Jang. "Fuzzy modeling using generalized neural networks and the Kalman filter algorithm." In: AAAI Association for the Advancement of Artificial Intelligence, vol. 91, 1991, pp. 762-767.

[23] MT. Güneşer. "Artificial intelligence solution to extract the dielectric properties of materials at sub-THz frequencies." IET Science, Measurement \& Technology, 2019, Doi:10.1049/iet-smt.2018.5356.

[24] S. Balci, A. Kayabasi, B. Yildiz. "ANN-based estimation of the voltage ripple according to the load variation of battery chargers, International Journal of Electronics." vol. 107. 1, 2020, pp. 17-27, Doi:https://doi.org/10.1080/00207217.2019.1591530.

\section{BIOGRAPHIES}

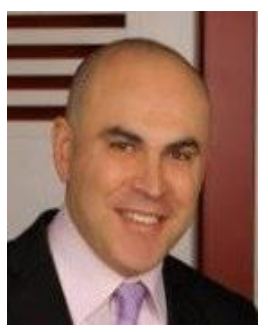

SELAMI BALCI He received the B.S., M.S. and the Ph.D. degrees in electrical education from the Gazi University, Ankara, in 1997, 2010 and 2016, respectively. Since 2018 , he is currently an Associate Professor at the faculty of engineering, department of electrical and electronics engineering, Karamanoğlu Mehmetbey University. His research interests include medium frequency power transformer, transformer design with the soft magnetic core material, transformer thermal analysis, inductor design, electromagnetic modeling with FEA software, and performance analysis of the power electronics circuits

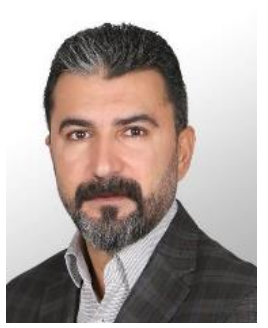

AHMET KAYABASI was born in 1980 . He received the B.S. and M.S. degrees in EEE from Selcuk University, Turkey, in 2001, 2005 respectively. In 2015, he received his Ph.D. degree in Electrical and Electronics Engineering from Mersin University, Turkey. From 2001 to 2015, he was a Lecturer in the Electronics and Automation Department of Selcuk University. He has been working as an Associate Professor in the Department of Electrical and Electronics Engineering at Karamanoglu Mehmetbey University. His current research interests include antennas, microstrip antennas, computational electromagnetic, artificial intelligence..

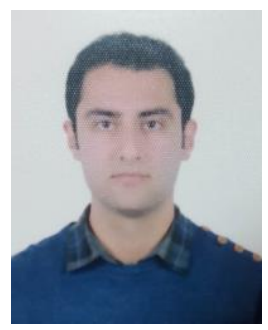

BERAT YILDIZ was born in 1993. He received the B.S. degrees in EEE from Eskisehir Osmangazi University in 2016 and M.S. degrees in EEE from Konya Technical University in 2019, Turkey. He has been working as a Research Assistant in the Department of Electrical and Electronics Engineering at Karamanoglu Mehmetbey University. His current research interests include robotics, image processing, artificial intelligence. 